\title{
On decoding and rewriting genomes: a psychoanalytical reading of a scientific revolution
}

\author{
Hub Zwart
}

(C) The Author(s) 2011. This article is published with open access at Springerlink.com

\begin{abstract}
In various documents the view emerges that contemporary biotechnosciences are currently experiencing a scientific revolution: a massive increase of pace, scale and scope. A significant part of the research endeavours involved in this scientific upheaval is devoted to understanding and, if possible, ameliorating humankind: from our genomes up to our bodies and brains. New developments in contemporary technosciences, such as synthetic biology and other genomics and "post-genomics" fields, tend to blur the distinctions between prevention, therapy and enhancement. An important dimension of this development is "biomimesis": i.e. the tendency of novel technologies and materials to mimic or plagiarize nature on a molecular and microscopic level in order to optimise prospects for the embedding of technological artefacts in natural systems such as human bodies and brains. In this paper, these developments are read and assessed from a psychoanalytical perspective. Three key concepts from psychoanalysis are used to come to terms with what is happening in research laboratories today. After assessing the general profile of the current revolution in this manner, I will focus on a particular case study, a line of research
\end{abstract}

H. Zwart $(\bowtie)$

Faculty of Science, Institute for Science, Innovation and Society, Radboud University Nijmegen, P.O. Box 9010, 6500 GL

Nijmegen, The Netherlands

e-mail: h.zwart@science.ru.nl

H. Zwart

Department of Philosophy and Science Studies, Radboud University Nijmegen, P.O. Box 9010, 6500 GL Nijmegen, The Netherlands

H. Zwart

Centre for Society and Genomics, Radboud University

Nijmegen, P.O. Box 9010, 6500 GL Nijmegen, The Netherlands that may serve as exemplification of the vicissitudes of contemporary technosciences, namely viral biomaterials. Viral life forms can be genetically modified (their genomes can be rewritten) in such a manner that they may be inserted in human bodies in order to produce substances at specific sites such as hormones (testosterone), neurotransmitters (dopamine), enzymes (insulin) or bone and muscle tissue. Notably, certain target groups such as top athletes, soldiers or patients suffering from degenerative diseases may become the pioneers serving as research subjects for novel applications. The same technologies can be used for various purposes ranging from therapy up to prevention and enhancement.

Keywords Psychoanalysis of science - Genomics . Synthetic biology $\cdot$ Biomimesis · Viral biomaterials

[My life] happened to coincide with the most dramatic burst of knowledge in the whole history of mankind... Life itself has yielded its secrets, its central mechanisms have been unravelled in intimate detail and its history has been probed back to [its] origin...

\section{Introduction}

The lines quoted above were taken from an autobiographical retrospect by Nobel Prize laureate Christian de Duve entitled Life evolving (De Duve 2002, p. vii). They convey a conviction, voiced in countless similar documents as well, and ubiquitously present in journals such as Nature and Science, that we are witnessing a scientific revolution of breathtaking dimensions, the scope and impact of which is comparable to those of previous epistemic upheavals, notably the one that irreversibly transformed the processes of scientific knowledge production in the 17th century. In 
the life sciences, the tale of the current revolution has evolved into a grand narrative. The recent quantum leap in knowledge, the narrative tells us, while building on the groundbreaking insights of Darwin and Mendel midway the nineteenth century, was heralded by the discovery of the structure of DNA by Watson and Crick in 1953, to be crowned by the completion of the sequencing of the human genome in 2000-2003. Indeed, sequencing the genomes of an exponentially growing number of species is among its core activities. Building on these previous milestones, the revolution still moves ahead, however, so that presently, we are entering the so-called post-genomics era, with synthetic biology as one of the new major frontiers of laboratory life. Whereas genomics was about "reading" and deciphering genomes - as the "scores" or the "Rosetta Stones" of life-synthetic biology is rather about re-writing or recomposing them, about writing DNA, using the bio-molecular alphabet nature herself has produced during the early days of evolution. This opens up broad vistas for societal innovation, or (to paraphrase a famous title of Friedrich Engels): what used to be mere "utopia" is increasingly becoming hard "science" (Zwart 2009).

In all these developments, a plethora of promises for society are entailed. When on June 26 2000, during their famous Press Conference, President Clinton, together with Francis Collins and Craig Venter, solemnly announced, from the East Room of the White House, that the grand effort to sequence the human genome- the Human Genome Project (HGP) — was rapidly nearing its completion, one of the most notorious claims made on the occasion was that "Our children's children will know the term cancer only as a constellation of stars". ${ }^{1}$ In other words, due to the current revolution in the life sciences, notably human genomics, cancer would soon be something of the past. Now, 11 years later, this rhetoric of promises strikes us as poignantly over-optimistic. In April 2010, the journal Nature devoted a special issue to assessing the outcomes of the HGP, "ten years after" as it were. In his own retrospect, Francis Collins, now Director of NIH, one of the world's leading funding agencies for biomedical research, asked the question "Has the revolution arrived?" (Collins 2010). His answer was: "Not yet". The basic outcome of the HGP is that life is much more complicated that was expected when the grand endeavour was launched in 1990 (Cf. "Life is complicated", Hayden 2010). Yet, the promises incited by genomics, notably for human health, are still in the air, at times even in amplified versions. They are simply transferred to newly emerging post-genomics fields, such as personalised genomics and synthetic biology. After deciphering the genome of humankind as such, the personal genome (i.e. the famous $\$ 1000$ genome) is now

$\overline{1 \text { http://www }}$.genome.gov/10001356. about to make its appearance, to enter the stage, while in the near future, we will increasingly be able to re-write (rather than only read) the genetic scores of living beings, to recompose the "music of life" (Noble 2006), reshuffling or reassembling its building-blocks, its notes and chords.

This is a telling example of what Sigmund Freud in The Interpretation of Dreams has called "displacement" ("Verschiebung", 1900/1942). The high expectations are still there, but they are transferred from the original object (the HGP) to alluring substitutes currently emerging, such as synthetic biology or personal genomics. The implication of this observation is not that the expectations involved should be simply discarded as science rhetoric, employed by research managers in their frantic search for novel streams of funding to keep their research teams alive in their perennial struggle for survival. Rather, in principle, these claims should be taken quite seriously. They are symptomatic of the desires that continue to fuel our contemporary will to know. Thus, the language of promises and expectations contains important cues for revealing and understanding the complex psychosocial dynamics of the research processes involved.

The HGP press conference was an instance of "science theatre" no doubt. The real-life daily plodding of scientists off stage, in less visible environments, carried out by whole armies of virtually anonymous (and often very young) researchers at work in laboratory settings, is driven by other, probably more mundane and less dramatic motives than the ones voices by Clinton, Collins and Venter as their science managers in command. Indeed, the distance between the picture presented by these elderly key protagonists "on stage" on the one hand, and the real world of science on the other, is likely to be quite considerable. Yet, precisely for this reason, we may see the press conference as a fascinating event, namely as an instance of what Freud, again in The Interpretation of Dreams (1900/1942), has called "Verdichtung" (condensation). Ideas and motives that tend to be present in research practices in a more or less subliminal, fragmented and distributed manner, diluted to such a degree that the researchers involved are usually hardly aware of them, are suddenly articulated and brought forward in a highly condensed and tangible form, as a highly symbolical focus event: a dream-like occasion (a brightly glittering press conference), as a scientific dream come true. On such a splendid occasion, the latent web of loosely associated, diffuse ideas becomes suddenly discrete and feasible-through condensation.

In this paper, I will argue that "displacement" and "condensation" are merely two examples of how psychoanalysis as a conceptual framework, a 'cobweb' of concepts so to speak, allows us to capture the meaning of such events and to make sense of the whirlpool of practices, discourses and events that make up the life sciences of 
today. The HGP and its various sequels, notably synthetic biology, can be seen as "case studies" ("Fallgeschichten"), readable in a "symptomatic" manner, so that psychoanalysis may help us to bring to the surface-and to critically assess - the basic desires and ambivalences of current research endeavours: the vicissitudes of laboratory life under the current heat wave of "Big Science".

Rather than presenting a comprehensive overview of psychoanalytic theory "in general", or of the psychoanalysis of science "as such" (which would involve a fairly voluminous monograph I guess), I will opt for a much more targeted approach, by outlining how a series of key psychoanalytical concepts may allow us to analyse and assess the dynamics of the contemporary life sciences. The "contemporary life sciences" still constitute a fairly wide and bewilderlingly diverse area of research, however, and various fields involved seem to lend themselves to a psychoanalytical approach,- areas such as brain research or reproductive medicine for instance. In this article, therefore, I will focus my attention on one particular branch of life sciences research that has received a relatively large amount of scientific attention-as well as research funding-during the past decade or two, namely the art of reading and (eventually) rewriting genomes. I will study the vicissitudes and discontents of research areas such as genomics and synthetic biology ("post genomics") as well as their potentials for human existence. For every concept, I will start my analysis with examples from genomics ("reading genomes"), functioning as a benchmark as it were, to subsequently shift attention to synthetic biology ("rewriting genomes") as a novel field. I opt for this combination not only because I see synthetic biology (or "synbio", as it is often referred to) as a sequel to genomics in various ways, but also because both fields tend to function increasingly in combination with each other, as the practices of reading and rewriting the building blocks of life are bound to be intimately entangled.

Yet, even genomics and synthetic biology may appear too complex and diverse to be dealt with sufficiently in one paper. Therefore, after outlining the relevance of psychoanalytical concepts for genomics and synbio (i.e. reading and rewriting genomes) in outline, I will use a case study approach and introduce one particular line of research within the broader bio-synthetic arena, but highly representative of the field (as will be explained more fully later on), namely the development of viral biomaterials. The basic question of this article thus is how psychoanalysis may help us to come to terms with genomics and synthetic biology as important components of the current revolution in the life sciences, in particular with the societal and bioethical implications of emerging viral materials as a case study (Fallgeschichte), an exemplification of the new science.
Concept 1: narcissistic insults

During the weeks and months preceding the gala televised HGP press conference described above, the human genome sequencing effort had turned into a massive spurt, involving competing teams who were almost dashing towards completion. ${ }^{2}$ Humankind was about to unveil the core of its identity, it was claimed, and the HGP was presented as an important milestone on the way to self-knowledge- $\gamma v \omega \dot{\theta} \theta$

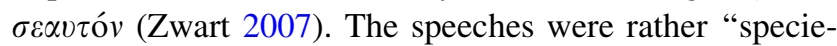
sist" in that they focused almost exclusively on human genomics (Zwart 2011) and this is remarkable, not only because the HGP involved the sequencing of a number of other species as well, but also because, notably from an anthropocentric perspective, the outcomes of the HGP seemed rather disappointing. The human genome contained no more than $\sim 23.000$ protein-coding genes, a remarkably small number in comparison to previous estimates (which ranged from 100,000 up to 350,000 ), while our genome proved remarkably similar to the genomes of other species, such as the chimpanzee and the laboratory mouse. We see ourselves as a unique and fascinating species whose creativity and intelligence is unprecedented in nature, as we are able to build and design a world, a socio-techno-cultural environment of our of our own making, significantly affecting the vicissitudes of life on earth as such. And yet, although we tend to set ourselves apart from the rest of nature, there is nothing in our genome that provides biological proof for any special status. We are the only species on earth, as far as we can tell, that seems able to understand and reflect on (and actively transform the conditions of) its own evolution, the only species on earth able to sequence its own genome, and yet there is nothing in our genome that seems to reflect any special talents. What Francis Fukuyama in Our posthuman future (2002) speculatively postulated as the Factor X-"A genetic endowment that distinguishes a human in essence from other types of creatures"-is actually absent and cannot be found. ${ }^{3}$ Indeed, in an influential article in the New York Times, Stephen Jay Gould (2001) called the publication of the human sequence a "humbling" experience. Finally, so it

\footnotetext{
2 "The race to complete the first human genome sequence had everything a story needs to keep its audience enthralled—right down to a neck-and-neck sprint for the finish by two fierce rivals. In the end, the result was basically a tie". (Nature 464, 1 April 2010, p. 649).

3 This mysterious "factor X" corresponds to what Jacques Lacan (2004) has referred to as the "object a" or as " $\varphi$ ", the missing thing, the evasive target of our will to know, the phantom-object of our epistemic desire, something which actually is not there and cannot be found-and therefore constitutes an issue of concern. Fukuyama's conviction that there simply must be a privileged set of typically and exclusively human core genes, somehow, somewhere, is a highly symptomatic exemplification of such as desire.
} 
seems, we are granted to privilege see ourselves in a mirror that is uncontaminated with the biases of narcissism.

According to Sigmund Freud (1917/1947), all major scientific breakthroughs are bound to entail serious narcissistic offences. We initially tend to see ourselves as a unique entity, a special ontological category, and as the centre of the world. The Copernican revolution made it clear that we not at all occupy a solid and central position in the universe, but rather dwell on a lonely blue planet floating around in godless and infinite-indeed "uncanny"_immensities. The Darwinian revolution subsequently made it clear that, biologically speaking, we are not a special kind of entity, but simply a species among others, the outcome of a process of evolution that will continue to shape and change us. And finally, psychoanalysis made it clear that we are not the autonomous masters of our own house, as by far the larger part our mental life functions in unconscious ways.

One could argue that the HGP entails yet another narcissistic insult. Our genome is not that different compared to other species. Rather, the human genome emphasises our basic relatedness with the rest of nature. Our genome is simply one of the thousands of genomes that are stored in the databases of contemporary science as digital archives of life. Still, the focus in our research remains preferably on our own genome, we continue to regard ourselves as our own "favourite species". And even if we study the genomes of other model species, such as C. elegans or the laboratory mouse, we predominantly do so because, indirectly, it is the human genome we are after.

It will not come as a surprise that we subsequently discern a similar narcissistic insult in the area of synthetic biology as well. On the one hand, we are humbled by the sophistication and effectiveness of the plethora of "biotechnological" devices developed by nature herself which we are only beginning to understand and appreciate and, to a limited extent, and with a limited level of effectiveness, employ. The basic toolboxes of biotechnology and biochemistry were not created by human beings, but by microbes in the course of evolution (notably during the earliest stages of life). On the other hand, we still see ourselves as agents, as entities that may consciously explore these natural toolboxes and employ them for new purposes, thus unleashing a new chapter in the history of both nature and technology. Nonetheless, it seems clear that, more than

\footnotetext{
4 "Uncanny" here in the literal sense of the term: "Un-heimlich". The ancient Greek universe (the "cosmos") was regarded as a series of protective spheres (globes) where human beings could feel embedded and at home (Sloterdijk 1999). It is telling that Pascal, who so eloquently voiced the frightening nature of the universe as a limitless abyss - with his phrase "Le silence éternel de ces espaces infinis m'effraie" (Pensées 206/201, Pascal 1958)—is generally regarded as the father of existentialism: the philosophy that regarded Angst as one of the basic moods of contemporary human existence par excellence (Cf. Lacan 2004).
}

in previous, more "faustian" stages in the history of technology, during which we saw ourselves as engineers regarding nature simply as a reservoir or raw materials, we now seem to appreciate the humbling ingenuity and sophistication of the biotechnologies of nature herself.

The American genomics pioneer of Japanese descent Susumu Ohno $(1987,1988)$ has even argued that human biotechnology basically comes down to a massive effort to "plagiarize" nature. Since life began a few billion years ago, he argues, the number of true innovations in evolution appears to have been "dismally small" (1987, p. 511). Most of the successful adaptations of living organisms have apparently been accomplished by extensive "plagiarisation" (idem) of those preciously few innovations via a limited set of duplication mechanisms. Furthermore, it appears that most of these true innovations have occurred at the very beginning of the saga of life. In the course of evolution, biological innovations have been duplicated to the point of redundancy. He goes on the argue, moreover, that the same tendency towards plagiarism pervades human knowledge and human culture. In Ohno's view, even geniuses seldom invent more than one novel modus operandi during their lifetime and civilization as a whole has largely been dependent upon plagiarizing a small number of creative innovations. Every gothic church can be regarded as a plagiarism of the original, similar to the fact that new genes have seldom been invented: rather, evolution involves creative re-use of what is already there. According to Ohno, both culture (and this includes science and technology of course) and evolution rely on extensive plagiarisation of tested themes. And this repetition of tested themes, he argues, has always been the hallmark of life, both of life in general and of human existence.

A symptom of the new humbleness is the current popularity of the concept of biomimesis (also known as biomimicry): the alleged tendency of emerging bio-technosciences to mimic and even consciously plagiarize the biotechnologies and biomaterials nature herself has developed in the course of billions of years of evolution. Ever since its introduction during the late 1990s, the concept of biomimesis (or biomimetics) has become quite popular among materials experts and synthetic biologists (Mann 1997, Bensaude-Vincent et al. 2002) and has made its appearance in top journals, such as Nature (Ball 2001; Sanchez et al. 2005). Bio-mimetic technologies are seen as much more "natural" (more adapted to natural systems) than previous forms of technological applications and interventions. Novel bio-techno-sciences not only claim to be able to permeate and explore but also to mimic and imitate the technologies that "nature herself" has developed, tested and improved. The objective is to reinsert artificial (man-made) systems in natural systems on a molecular and micro-level in such a way that the artificial 
elements become optimally embedded. The ultimate goal is to reintegrate the techno-sphere into the biosphere (mutual pervasiveness of technology and nature). According to the Sanchez et al. (2005), biomimesis is "one of the most promising scientific and technological challenges of the coming years" (p. 285). While in the past the focus was on using technology to improve nature, nature's "pool of ideas" now increasingly becomes a source of innovation and improvement for molecular technology. Thus biomimetic devices convey the intriguing (but as yet contestable) promise of optimal interaction with their environment, while safeguarding the integrity of human bodies and brains. Yet, once these tool boxes of nature have been made available, the tendency of human technology to go beyond natural constraints is bound to manifest itself again. Synthetic biology clearly is an exemplification of this paradoxical trend. On the one hand, we are fascinated and even humbled by the sophistication of the tool boxes of nature. On the other hand, we want to enrich them and employ them, aiming at novel targets, producing novel entities, new biosynthetic hybrids.

The term "biotechnology" itself is at the heart of the dispute. On the one hand it is often claimed that biotechnology is something exclusively human. From this perspective, the tools developed by "nature" and natural species are simply seen as "biology", while biotechnology is regarded as something typically belonging to us. In fact, many authors are even more restrictive, using biotechnology exclusively for the biotechnological repertoires that have been developed in the context of the "biotechnological revolution" (since $\sim 1975$ ), such as genetic modification of crops or of research animals (such as genetically modified laboratory mice). Others, are more reluctant to see the development of biotechnologies as an exclusively human thing. Regardless of one's position in this debate, the debate as such can be regarded as a symptom of the "narcissistic offence" inherent in contemporary science. On the one hand, we simply use the techniques and pathways for modification developed by nature herself. On the other hand, we often do so in unprecedented ways, so that biotechnology allows us to redefine our specialness. We mimic nature, but in a conscious and innovative manner, driven by a will to knowledge, as a manifestation of our will to (gain) power (over nature) and to emancipate ourselves from nature.

Concept 2: biosynthetic hybrids as instances of the Uncanny

Another concept that seems highly relevant when it comes to understanding the current revolution is Freud's concept of the "uncanny" ("Das Unheimliche", 1919/1947). It has always played a role in responses to and deliberations concerning the current life sciences revolution, also during the genomics era. The idea is that laboratory science has the tendency to produce monsters-grotesque as well as beautiful ones, formidably huge as well as invincibly small ones-behind closed doors, hybrid entities in the boundary zone between the living and the artificial.

An telling example of a document that sets out to address the societal implication of the genomics revolution, as a key segment of the broader life sciences revolution, is Michael Crichton's world-famous novel Jurassic Park, published in the same year in which the HGP was launched (1990). The goal of the novel is to explore, by way of a literary experiment, what will come of this new scientific power when it falls in the hands of scientifically trained pioneers and entrepreneurs. The focus this time is on the animal realm. What would it mean if extinct species, by sequencing, reconstructing and cloning (that is: de-coding and rewriting) their paleo-DNA, could be reanimated and brought to life again, thereby turning dinosaurs into research animals and palaeontology into an experimental ethology?

Extinct Jurassic species, re-emerging in the era of the technical reproducibility of life, would certainly represent the category of the uncanny and the monstrous, not only because of their enormity and formidable bulk, but also because these living specimens are biotechnological hybrids: they find themselves somewhere in the intermediary zone between the natural and the artificial. They are at the same time extremely wild animals and man-made laboratory products.

The Frankenstein-scenario or Frankenstein-complex, as it was originally conceived by Mary Shelley in her classic novel (Wollstonecraft Shelley 1818/1968), basically reflects that, from the beginning of the $19^{\text {th }}$ century onwards, ${ }^{5}$ life scientists have been engaged in producing novel entities (biotechnological hybrids) that sooner or later are introduced in the life world and in society, with unforeseen, but initially often harmful, consequences. This not only applies to modified microbes or modified mice, but would also go for reanimated extinct species. Indeed, even the first children born with the help of IVF were "heralded" as "Frankenstein babies" in the 1970s (Turney 1998).

\footnotetext{
5 The Famous passage in the Introduction to her novel, where she described her dream about a young scientists who has finally managed to put his artificial but living "thing" together, can be regarded as the Ur-Scene, the primordial scene of the contemporary life sciences: My imagination, unbidden, possessed and guided me, gifting the successive images that arose in my mind with a vividness far beyond the usual bonds of reverie. I saw-with shut eyes, but acute mental vision-I saw the pale student of unhallowed arts kneeling beside the thing he had put together. I saw the hideous phantasm of a man stretched out, and then, on the working of some powerful engine, show signs of life, and stir with an uneasy, half-vital motion. Frightful must it be ... His success would terrify the artist; he would rush away from his odious handiwork, horror-stricken. He would hope that, left to itself, the slight spark of life which he had communicated would fade... (p. 263/264).
} 
This "complex" is also at the heart of Crichton's intriguing novel. Millions of years after their extinction, posthumously as it were, the dinosaurs are suddenly invited into the manmade Ark (in the form of a privately-owned tropical island) in order to survive the great deluge, the great wave of mass extinction that wiped them off the face of the earth after all. This involves them in a process of domestication: the taming of the monster. In the case of Crichton's novel, two types of preventive measures, instances of policies of containment, have been taken in order to make the world immune, as it were, against collateral dinosaur damage. First of all, a particular gene has been knocked-out, deleted from the code, so that the dinosaurs are unable to sufficiently feed themselves, without support from humans. Without special food ingredients, provided by their human caretakers, they would be unable to survive. Thus, they cannot really be regarded as wild type dinosaurs. They are turned into Mangelwesen as it were (Gehlen 1962), to keep them in place.

From a psychoanalytical viewpoint one could say that this is done to keep them perpetually in a situation of oral dependence, depriving them of the possibility to develop into mature, adult individuals who can take care of themselves. They are subject to a policy of genome-based animal husbandry. Humans try to stay in control by employing a form of "pastoral power": these monsters are to remain dependent on us as their feeders and keepers forever. Yet, as becomes apparent in the course of the novel, the designers and re-animators of these test animals have underestimated the creativity of life. Living beings are problem-solvers, and living entities will find a way out, there will always be surrogates and alternatives somewhere along the road to independence and freedom.

The second preventive measure is the decision to select only the female eggs, so that the theme Park is inhabited by female versions of dinosaurs only. This is another major effort that is employed in order to domesticate the monster. Not in the sense that females are more easily to tame or handle, or something like that (on the contrary, in Crichton's novel it is stated that female dinosaurs are actually stronger and more dangerous than their male counterparts), but again in the sense that they are deprived of the possibility to become adult living beings. This time, they are deprived of the possibility to reproduce. Psychoanalytically speaking, the decision to only allow specimen of one of the two sexes to mature, means that an important link in the pathway of reproduction is lacking, so that the inhabitants of the Park represent a "castrated" version of the original (Jurassic) dinosaur community. The reproductive organ the constitutes the bridge between two sets of DNA as it were is missing. The human stewards in this artificial Jurassic paradise want to remain in control, they are the only ones entitled to select and fertilize the eggs and they do not want to grant this right to the dinosaurs themselves. In
Frankenstein, the archetypical monster of the modern life sciences par excellence is in a similar manner deprived of the possibility to reproduce when Victor Frankenstein decides to destroy the female version he promised (and almost managed) to create. By being able to reproduce, the dinosaurs would be awarded the right to take their evolution, their destiny, in their own hands, they would begin to reproduce and migrate like any other species and would populate and colonize the world on their own accord.

The alternative scenario, an autonomously reproducing dinosaur community, would present a rather uncanny prospect. By way of an oedipal revolt, these biotech monsters, as soon as they are able to procreate, would increasingly ignore the plans their creators originally had in stall for them. They would evolve from a tourist park attraction into a biological species in search of an optimal habitat, no longer instrumental to anthropocentric purposes. In the case of carnivores, they will see us simply as edible mammals, as prey, rather than as stewards. This is something to forego. But again, nature proves more flexible and creative that the designers of the Park presumed. The dinosaurs simply change their sex, as amphibian species in nature under certain circumstances do, and thus reassume control over their own reproduction. They differentiate into two sexes, assuming adult male and female identities, from a psychoanalytical perspective an important oedipal move on the road towards biological self-determination.

Perhaps even more than in the case of genomics, which is basically about reading and reproducing existing genomes, the category of the uncanny applies to emerging biosynthetic hybrids of the synthetic biology revolution. According to Freud, the category of the uncanny becomes relevant as soon as the borderline between the living and the non-living, between the natural and the artificial, becomes blurred, and this seems to apply to the plethora of artificial, biomimetic contrivances, bioimplants, biosensors and other synbio products that are currently being designed worldwide. Again, rather than acting as mere artefacts that will simply function as we intended them to function, they may sooner or later begin to live a life, a career of their own, entering the tissues and arteries of society. Sooner or later, they may pose a threat to the integrity of human bodies and brains. Increasingly, our brains and bodies may be endangered by the intrusion of pervading and invading biomimetical devices produced by new combinations of the building blocks of life. But I will flesh out this scenario in more detail when discussing the case study of viral materials later on.

Like Jurassic Park and its sequel The lost world, the novel Next (2006), the last novel Michael Crichton published before his death, is a genomics novel, but now the focus has shifted from the animal realm (animal well-being and behaviour) to the human realm (biomedical and personal health issues). In this novel it is fleshed out how, due 
to the current biorevolution, human individuals are becoming the managers of their own health status, of their own biographies. Increasingly, individuals begin to see themselves as genome entrepreneurs, using personal genome information as their starting capital as it were, whilst human bodies are redefined as reservoirs of highly valuable resources (genes, cells, tissues and the like as entities with market value). Yet, in this novel, the highly dramatic, exotic and spectacular, Discovery Channel-like ambiance of Jurassic Park has given way to the atmosphere of a Soap. In displaying individuals on their hunt for genes that may explain, or help them to improve, their personality and their conduct, the reading and rewriting of genomes has evolved into something highly trivial and banal. Yet, this may mean that the uncanny (literally: the un-homely, das Unheimliche) is well on its way to become domesticated and embedded, so that the art of decoding and recomposing genomes has already begun to enter ordinary life.

\section{Concept 3: pandemics of technology}

Uncanny biotechnological hybrids are not only threatening entities in themselves, they are even more intimidating because, sooner or later, they are bound to escape from the laboratory, they will get out of control, thus quickly evolving into a scourge for humanity at large. Indeed, as Ulrich Beck (1992) has argued, in contrast to earlier epochs, the hazards and catastrophes of contemporary biosocieties are induced and introduced by the technosciences themselves. We already noticed that biotech hybrids and similar monsters have the tendency to proliferate, to spread. In other words, the monster-archetype tends to be closely associated with a proxy archetype, namely that of the man-made, biotechnological pandemic, involving novel biomimetic artefacts that, after their incubation period in contained laboratory settings, will invade and inflame societal realms, niches and tissues on a massive scale. New biosynthetic entities are first introduced in special protected environments or niches (such as research laboratories, but also specialized hospitals and military facilities), but are bound to spread and disseminate from there sooner or later into society and daily life. Sooner or later, they will become highly pervasive.

The genomics revolution itself resulted from a kind of technological contagion, the massive proliferation and spread of high throughput sequencing facilities throughout laboratory networks worldwide. And now, during the years to come, a wave of genomics information will begin to affect health care through biobanking and personal genome information. For synthetic biology, this archetype will even be more pertinent, so it seems. New synthetic bio-objects will spread through the realms and tissues of society, quickly evolving, assuming unpredicted roles and functions, used by various groups of users for unintended purposes, taking on a life of their own. Immunization policies in the form of regulatory regimes will have to be put in place to contain and govern the turbulence of these developments.

The pandemic archetype is notably relevant because synthetic biology is an important part of the emerging field of do-it-yourself biology (Wohlsen 2011; Cf. Penders 2011). Professional laboratories increasingly seem to lose their monopoly over the production of synthetic bioproducts (provided, that is, that such a monopoly ever existed). Biohackers may well create an online open-source global supermarket for synthetic biological entities or ingredients. Or, as Wohlsen puts it: Biopunk carries the message that slowly, steadily, we could all become authors of a ubiquitous and "democratic" biology. Thus, a synbio version of the self-help movement for a broad variety of selfempowered individuals, using genetically modified viral or microbial colonies in vitro for brewing their own homemade opium, Prozac or Ritalin, may well be awaiting us. But I will further elaborate this prospect in the context of my case study: the emergence of viral materials.

\section{Viral biomaterials: a case study}

My case study concerns an ongoing interdisciplinary collaborative project of philosophers of science with researchers of the Institute for Molecules and Materials (IMM) at the Faculty of Science, Radboud University Nijmegen, the Netherlands. ${ }^{6}$ IMM studies how viruses can be used for producing biomaterials. By adding gene segments to plant viruses, self-replicating, biomimetic enzymes can be generated, for instance for producing cellular energy (ATP), hormones (such as testosterone or EPO), various vital enzymes (such as insulin), neurotransmitters (such as dopamine) or bodily tissues (such as bone or muscle tissue). Viruses can not only be used for storage and transport of genetic material, but also as scaffolds, reaction vessels, nanotemplates or synthetic platforms for producing self-replicating compounds or for self-assembling enzymes and catalytic products that stimulate various cellular processes. Enzymes encapsulated in a virus can be used for biodetection or for setting up selfassembling systems for producing composite materials such as bodily tissues. Thus, along the lines of biomimesis,

\footnotetext{
${ }^{6}$ IMM is an interdisciplinary research institute of international prominence, active in areas ranging from nanoscience to biochemical synthesis. Its mission is to understand and manipulate properties of functional molecules and materials. In 2010, the Nobel Prize for physics was awarded to Andre Geim (former associate professor and currently extraordinary professor at IMM) and Konstantin Novoselov (for his Ph.D. research conducted at IMM) for their work on graphene.
} 
"nature's own approach" (self-assembly) is used to produce a broad variety of biomolecules (Carette et al. 2007; Comellas-Aragonés et al. 2007). It is a key example of how bionanoscience is about to pervade human bodies.

To give a concrete example of what this means, in the case of patients suffering from Parkinson's disease, or identified (on the basis of their personal genome) as being at a risk for developing this neurodegenerative affliction, viral implants may be inserted into the substantia nigra of their brain to produce dopamine, either for therapy or for prevention. Thus, patients suffering from degenerative and as yet incurable diseases may be provided with new options and prospects for the future. Yet, this is merely one example and as viral biomaterials constitute a generic approach, they can be applied to a broad variety of purposes, for therapy and prevention (in clinical settings), but also for "performance enhancement". Thus, besides therapeutic applications, various options for healthy individuals may come into view as well, notably in the context of special professions (involving individuals exposed to extraordinary risks) such as the military and top athletes. Soldiers of the future may be equipped with biosensors (miniaturised biomimetic sensing devices) for discerning ultra-red light (body heath) in the dark, or with self-replicating systems for wound healing. Top athletes may (either for purposes of injury prevention, or for performance enhancement, or both) use micro-implants to produce hormones (such as EPO) or strengthen particular tissues at risk. In short, a plethora of options is emerging and the boundaries between therapy, prevention and enhancement are bound to become increasingly blurred. The societal divide may increase between those who are informed or affluent enough to use these applications to manage their mental and physical condition, or even strengthen their performance, and those who are less willing or able to do so.

Yet, these emerging bio-ethical issues must be addressed against the backdrop of a broader perspective. The case could be made that we are entering a new chapter in the history of human embodiment. So far, technology basically produced protheses in the form of visible "extensions" or replacements that allowed human beings to transform themselves from an unfinished, and therefore still highly plastic, Mangelwesen (Gehlen 1962) into an optimally adapted entity: modern human beings functioning in a complex environment of their own making. Now, technology is taking a new "Turn", in the heideggerian sense of the term, by entering our brains and bodies on a molecular and microscopic level and by producing bioimplants that may become intimately embedded.

The optimalisation of eye sight may be used as an example here of how technology is currently evolving: from a pair of highly visible glasses covering the eyes (classical optics), via virtually invisible plastic contact lenses (already touching the surface of the eye), to laser treatment, up to embedded biomaterial implants in the lens or retina-perhaps even in parts of the brain associated with visual functioning. Thus, novel artefacts are entering and about to nestle themselves in our sense organs and eventually maybe even in our neural networks. Actually, in the essay in which the concept of the uncanny is developed, Freud (1919/1947) himself pays special attention to human eyes, using as his key exemplification of the uncanny a Hoffmann story about a young student who falls in love with someone because of her mysteriously attractive and fascinating, but artificial eye-balls.

To what extent can psychoanalytical concepts allow us to assess the emerging issues in synthetic biological approaches to human health such as the case of viral material implants? I will "apply" the three (highly interrelated) concepts in the same order in which they were introduced above.

\section{The narcissistic offence}

With viral implants appearing on the horizon, the human body seems besieged. Closely related to narcissism and the narcissistic offence is the emphasis on the integrity or inviolability of the human body. There is a certain sense of Apollonian and aesthetic completeness, wholeness and soundness attached to our intuitive elevation of the human torso, female or male. At first glance, we seem perfectly finished, we do not seem to be lacking anything,- - a narcissistic appraisal grounded in what Lacan (1966) referred to as the "mirror" experience. Yet, whenever human bodies are opened up, by surgery, by anatomical dissection, by an MRI-scan, or by any other biomedical devices, a slightly different perspective emerges. Whenever our blurry, visceral insides, our intestines are revealed, more or less uncanny and narcissistically insulting images may emerge, such as the view of the human body functioning as a mere machine, or as a biochemical plant producing huge amounts of waste, besides a large number of functional biochemical products, or as a kind of ecosystem inhabited by millions of micro-organisms who actually are responsible for the broad range of processes we traditionally summarize under the heading of "metabolism". Thus, rather than seeing human as "individuals" (literally: indivisible entities), ${ }^{7}$ the human body seems submerged in the biochemical processes of life, and the human as a "person" or "subject" tends to disappear from view. In fact, the integrity of our bodies has been violated since time immemorial, by the constant influx of viral and microbial life forms, unconsciously, without our awareness, let alone

\footnotetext{
${ }^{7}$ Not only the term "individual", also the term "integrity" etymologically refers to the wholeness of the human body.
} 
our consent. In the era of synthetic biology, the idea emerges that nature (human bodies) on the one hand and technology (pharmaceuticals, prostheses and implants) on the other do not constitute a dichotomy, but should rather be seen as a "Dionysian" continuum: the human body as a pool of chemicals and as a reactor vessel for myriads of biochemical processes. Our body emerges as a complex, interactive system, rather than as a sculpture. And parts of this system may be re-written or re-designed as our systems are mixtures of sophistication and flaws, of functional and dysfunctional elements.

Moreover, ours is an era in which societal demands and expectations in terms of physical condition, longevity, physical attractiveness, cognitive and physical performance and the like tend to become increasingly severe. Rather than via Darwinian selection, which is a notoriously slow, tedious and violent process, we will try to meet these demands by actively working on ourselves, through improvement and repair. Health is the temporary outcome of a process that may increasingly be in need of input from contemporary biotechnosciences. We are open for improvement. And viral implants may be seen as providing an optimal set of vectors for such a view of ourselves. We may continue to work on ourselves in a fine-grained, technologically sophisticated manner. Rather than poisoning our whole system with traditional drugs, alcohol, psychopharmaceutics or tranquilizers, we may enact our repair or improvement work "on site", on a microscopic level. On the one hand, we acknowledge that we are Mangelwesen, in need of corrective interventions, and that our microbial processes are quite similar than those of viruses, microbes, or other forms of life. On the other hand, we can still see ourselves as special and unprecedented, namely as the only form of life that is actually able to see itself as "unfinished" and therefore really able to actively manage and rewrite the scores of its own life. And this may give rise to the concern, voiced by Fukuyama (2002) and others, that we currently run the risk of deploying technologies that are the products of our intelligence and freedom (of "human nature"), to undermine the very basis (genetically, neurologically and otherwise) of this intelligence and freedom: human nature under siege.

\section{The uncanny}

The uncanny, the second concept discussed above, is closely related to narcissism, as we have seen. As Freud explains in his article, the category of the uncanny notably applies to hybrid life forms, boundary elements between the natural and the artificial, the human and the animal, the living and the non-living. From this perspective, viral life forms are already highly interesting in themselves as candidates that may optimally exemplify the uncanny as an ontological category. Constituting the boundary zone between the living and the non-living, viruses are already an exemplification of this idea. They are by definition an item of uneasiness and concern. They are alive, but continuously mimicking and parasitizing upon their favourite model species. Our immune system, indeed: the human corpus as such (almost completely covered by a protective layer of skin), seems designed with the explicit purpose of keeping them out. What an uncanny idea, then, to invite them in, in the form of viral biomaterials. The use of viral biomaterials would constitute a new wave of viral and microbial infusions and invasions, after vaccination and similar biomedical techniques that were introduced in the era of Pasteur and Koch.

Like the macro-monsters of Jurassic Park, we may believe that we will be able to contain them, keep them in place, but we know from experience that viruses are flexible, adaptive and creative, and evolving at a very high pace. Moreover, we know (and this is one of the narcissistic offences to which we are exposed) that we are not really in-dividuals in the sense of stand-alone entities, but rather inhabited by a plethora of viral and microbial life forms. How will new viral entities interact with our inhabited bodies as their environment? Will they awaken for instance the retroviral sleeping beauties slumbering in our nuclei? The genome itself is an archive that contains the traces of a long history of invasions of nomadic viral life forms, entering our cells, and even the nuclei of our cells. A huge part of what was formerly known as junkDNA contains the traces and sediments of previous viral experiments. A new chapter in this dramatic history seems to be unleashed under the heading of synthetic biology.

Yet, at the same time, this knowledge can also be used to emphasize that the introduction of viral materials into human bodies, albeit intentional this time, is really nothing new. It is simply part of the drama of life, although we now intend to do it in a targeted and tailored manner.

\section{The archetype of the biotechnological pandemic}

Finally, there is the apprehension that novel synthetic bioproducts such as viral biomaterials may become something of a biotechnological pandemic. This is connected to the archetype associated with the biomedical field as such, the idea of a iatrogenic infection, cause by an agent that is put into this world on purpose by biomedical experts themselves, with the best of intentions no doubt, but with unforeseen consequences in terms of collateral damage. The idea is that, as viral biomaterials enter various societal environments, will imbue the valves and tissues of society, they will begin to evolve in various directions, they will be adapted by various users for unforeseen and unintended and at times contentious goals. Patients suffering from 
degenerative diseases and top athletes will act as pioneers. They are the "test animals" of our biosocieties as it were, who expose their own bodies to novel options and ideas. They will be the first to allow viral implants to enter their bodies and brains. Gradually, these therapies may spread to other patients groups as well as healthy individuals, so that therapy gradually gives way to enhancement.

\section{Conclusion and prospects for the future}

Analysing contemporary biomedical technosciences through the lens of a psychoanalytic conceptual framework is a revealing and rewarding exercise, notably when these concepts are employed during the exploratory stages of assessment, with a focus on newly emerging technoscientific fields, for the purpose of elucidation as it were. As the technosciences at hand continue to evolve, however, these psychoanalytical concepts will increasingly become connected with more concrete bioethical issues and deliberations as well, in various ways. The concept of the narcissistic offence, for instance, but also the concept of the uncanny, will notably prove relevant for bioethical deliberations concerning the integrity and inviolability of the human body, as well as for reflections on the implications these developments may have for human autonomy and self-determination. As the genetic and biomolecular basis for autonomy and bodily integrity is being challenged and redefined, a psychoanalytical reading may allow us to reconsider en reframe the basic content of these key bioethical concepts. The concept of the synbio pandemic, on the other hand, is predominantly connected with issues such as justice and risk. Justice because on the one hand it may strengthen the democratization of new technologies as soon as they leave the professional laboratories of top research groups or high tech industries and enter our kitchens and garages, while on the other hand it may deepen the divide between the literate and illiterate in terms of self-management and the prospects offered by synthetic biology in this respect. Risks because of the difficulties in predicting and governing the future evolution of these technologies in societal environments. This paper presents the building blocks or basic ingredients for what may evolve into a more comprehensive psychoanalytic reading of the contemporary biomedical and bio-molecular life sciences.

Acknowledgments this article builds on papers presented at the SYBHEL Conference "Synthetic Biology \& Human Health: Conceptual Foundations, Methodology \& Ethical Frameworks" (Bristol, 27-28 June 2011) and at the 25th European Conference on Philosophy of Medicine and Health Care (Zürich, 17-20 August, 2011). The research presented is part of the Centre for Society and Genomics Research Programme CSG Next, funded by the Netherlands Genomics Initiative (NGI).

Open Access This article is distributed under the terms of the Creative Commons Attribution Noncommercial License which permits any noncommercial use, distribution, and reproduction in any medium, provided the original author(s) and source are credited.

\section{References}

Ball, P. 2001. Life's lessons in design. Nature 409: 413-416.

Beck, U. 1992. Risk slociety: Towards a new modernity. London: Sage. Bensaude-Vincent, B., H. Arribart, Y. Bouligand, and C. Sanchez. 2002. Chemists and the school of nature. New Journal of Chemistry 1: 1-5.

Carette, N., R. Nolte, J. van Hest, et al. 2007. A virus-based biocatalyst. Nature nanotechnology 2: 226-229.

Collins, F. 2010. Has the revolution arrived? Nature 646(7289): 674-675.

Comellas-Aragonés, M., R. Nolte, et al. 2007. A virus capsid based nanoreactor. Nature Nanotechnology 2: 635-639.

Crichton, M. 1990/1991. Jurassic Park. London: Arrow/random house.

Crichton, M. 2006. Next. New York: Harper Collins.

de Duve, C. 2002. Life evolving. Molecules, mind and meaning. Oxford/New York: Oxford University Press.

Freud, S. 1900/1942. Die Traumdeutung. Gesammelte Werke II/III. London: Imago.

Freud, S. 1917/1947. Eine Schwierigkeit der Psychoanalyse. Gesammelte Werke XII. London: Imago, pp. 3-12.

Freud, S. 1919/1947. Das Unheimliche. Gesammelte Werke XII. London: Imago.

Fukuyama, F. 2002. Our posthuman future. Consequences of the biotechnology revolution. New York: Farrar, Straus and Giroux.

Gehlen, A. 1962. Der Mensch. Seine Natur und seine Stellung in der Welt. Frankfurt/Bonn: Athenäum.

Gould, S.J. 2001. Humbled by the genome's mysteries. USA: New York Times, February 19.

Hayden, E. 2010. Human genome at ten: Life is complicated. Nature 464: 664-667.

Lacan, J. 1966. Écrits. Paris: Éditions du Seuil.

Lacan, J. 2004. Le Séminaire 10: L'angoisse. Paris: Éditions du Seuil.

Mann, S. 1997. Biomimetic materials chemistry. New York: Wiley.

Noble, D. 2006. The music of life: Biology beyond the genome. Oxford: Oxford University Press.

Ohno, S. 1987. Repetition as the essence of life on this earth. Hematology and Blood Transfusion 31: 511-518.

Ohno, S. 1988. On periodicities governing the construction of genes and proteins. Animal Genetics 19: 305-316.

Pascal, B. 1958. Pensées (2 tomes). Paris: Hachette.

Penders, B. 2011. DIY biology (book review). Nature 472: 167.

Sanchez, C., H. Arribart, and M.M. Giraud Guille. 2005. Biomimetism and bioinspiration as tools for the design of innovative materials and systems. Nature Materials 4: 277-288.

Sloterdijk, P. 1999. Sphären II: Globen. Frankfurt am Main: Suhrkamp.

Turney, J. 1998. Frankenstein's footsteps: Science, genetics and popular culture. New Haven \& London: Yale University Press.

Wohlsen, M. 2011. Biopunk: DIY scientists hack the software of life. New York: Barnes \& Noble.

Wollstonecraft Shelley, M. 1818/1968. Frankenstein; or, the modern prometheus. In Three gothic novels, ed. Fairclough, P, Harmondsworth: Penguin.

Zwart, H. 2007. Genomics and self-knowledge. Implications for societal research and debate. New Genetics and Society 26(2): 181-202.

Zwart, H. 2009. From utopia to science: challenges of personalised genomics information for health management and health enhancement. Medicine Studies 1(2): 155-166.

Zwart, H. 2011. Towards an eco-centric view of human existence: Implications of genomics for the environmental zone. Genomics, Society and Policy 6(2): 40-55. 